\title{
Mini games for professional awareness in introductory psychology
}

Citation for published version (APA):

Hummel, H., Nadolski, R., Slootmaker, A., \& Eshuis, J. (2019). Mini games for professional awareness in introductory psychology. In L. G. C., A. L. M., \& I. C. T. (Eds.), INTED 2019 conference proceedings: 13th International Technology, Education and Development Conference Valencia, Spain. 11-13 March, 2019 (pp. 179-184). IATED Academy. https://doi.org/10.21125/inted.2019.0086

DOI:

10.21125/inted.2019.0086

Document status and date:

Published: 01/01/2019

Document Version:

Peer reviewed version

Document license:

CC BY-ND

Please check the document version of this publication:

- A submitted manuscript is the version of the article upon submission and before peer-review. There can be important differences between the submitted version and the official published version of record. People interested in the research are advised to contact the author for the final version of the publication, or visit the DOI to the publisher's website.

- The final author version and the galley proof are versions of the publication after peer review.

- The final published version features the final layout of the paper including the volume, issue and page numbers.

Link to publication

\section{General rights}

Copyright and moral rights for the publications made accessible in the public portal are retained by the authors and/or other copyright owners and it is a condition of accessing publications that users recognise and abide by the legal requirements associated with these rights.

- Users may download and print one copy of any publication from the public portal for the purpose of private study or research.

- You may not further distribute the material or use it for any profit-making activity or commercial gain

- You may freely distribute the URL identifying the publication in the public portal.

If the publication is distributed under the terms of Article 25fa of the Dutch Copyright Act, indicated by the "Taverne" license above, please follow below link for the End User Agreement:

https://www.ou.nl/taverne-agreement

Take down policy

If you believe that this document breaches copyright please contact us at:

pure-support@ou.nl

providing details and we will investigate your claim.

Downloaded from https://research.ou.nl/ on date: 26 Apr. 2023 


\title{
MINI GAMES FOR PROFESSIONAL AWARENESS IN INTRODUCTORY PSYCHOLOGY
}

\author{
H. G. K. Hummel, R. J. Nadolski, A. Slootmaker, J. Eshuis \\ Welten institute / Faculty of Psychology and Educational Sciences, \\ Open university of the Netherlands (NETHERLANDS)
}

\begin{abstract}
Introductory psychology courses in higher education usually focus on disseminating psychological theory and lack application of this knowledge to the practical context of work. We expect a game-based approach to support more active and experiential learning, and develop a series of mini-games to increase awareness of study specialisations and careers in psychology.

This short 'work in progress' paper first describes the instructional design of these mini-games that provide our psychology students with more authentic, rich and active learning environments. We then describe our research design with some preliminary findings. We administered questionnaires before and after gameplay and collected logging data on gameplay. Participants were allocated randomly to four experimental groups that used variants of the games, differing in assignment order (fixed or free, so more active) and number of sources (one or more per assignment, so richer). At the time of submitting this paper, 12 mini-games are available that have been studied by 80 students (complete datasets).

Preliminary results show a positive treatment effect of gameplay on professional awareness, as indicated by a $12 \%$ knowledge increase about work practice. Students evaluate the gameplay (authenticity, usability, flow) and setup of game content (learnability) as 'more than sufficient' to 'good'. Some between-groups differences within the $2 \times 2$ game variants were found. For instance, a fixed order of assignments was found to produce more efficient learning, and the provision of more sources was found to increase feelings of authentic learning. Between-group comparisons did not reveal significant differences on other dependent variables studied (like motivation, flow, usability, learnability, grade).
\end{abstract}

Keywords: mini games for learning, professional awareness, experience psychology, pedagogical scenarios, authentic cases

\section{INTRODUCTION}

Active learning through meaningful and playful practice has been shown to positively influence students' professional awareness (e.g., [1], [6], [10]). Positive effects of acquiring more transversal skills on both professional insight and (as a consequence) involvement during academic and professional careers, have been reported. When students have a more concrete idea of their own interests and preferences, they can better engage with future careers. Such 'professional games' provide a learning context that simulates the context in which students will apply their learning. In that way, learning activities become more relevant and motivating, and increase the likelihood that acquired skills will actually transfer to real-world situations ([4], [5]). Such gaming or playful learning in context is recognized as an activity that can enhance students' motivation to learn and lead to better learning results when compared with more traditional learning (e.g., [3], [11]). Active learning involves the learner in activities aimed at self-directed learning ([2]). Situated (or contextually "rich") learning provides the learner with meaningful experiences to experience consequences of actions through "rich media" presentation formats ([4]). As with active learning, a "richer" context is assumed to contribute to more sustained and self-directed learning. Both learning paradigms limp on the idea that motivation initiates and sustains learning if adequate learner support is given ([7],[10]), and that initial motivation arises from tasks or experiences ([8], [9]).

Our instructional design departs from an overarching scenario that connects authentic cases from practice to learning activities in education, represented through 16 scenario-based mini-games (of which 12 were available at the time of this study). At the basis of the scenario lies a multi-facetted problem family that is to be analysed and treated from four main psychological perspectives, that are offered as specialisations in our Master program Psychology (being clinical psychology, labour and organisation psychology, life counselling psychology, and health psychology). Professional competences practiced by (carrying out practical assignments within) the mini-games (each takes approximately 1-2 hours to study) are e.g.: how to communicate with patients; how to conduct tests and therapies in actual practice; 
how to conduct an anamnesis during intake; how to build and analyse client files; and how to deal with practical dilemmas, useless information and unexpected events.

All scenarios have been worked out in close collaboration with domain experts from our faculty of Psychology. Elaborated scenarios were implemented and worked out into mini-games using our homebrew and dedicated EMERGO platform for developing and distributing professional games for experiential learning ([13]). Such mini-games make students play an active and explorative role in authentic professional settings, which is expected to increase professional awareness and involvement. Gameplay supports students in finding out more about their values, beliefs and strengths (personal identity), and in finding out more about interesting specialisations and preferred career options, as well as tools and networks to get there (professional identity). Where authentic cases show overlap, minigames can have a collaborative or integrative nature between specialisations.

Figure 1 provides some more concrete insights into the mini-games. The four screengrabs depict: (upper left) a. the (twelve) mini-games with respective domain experts, as well as the (virtual) supervisor (on the right); (upper right) b. a list of assignments available within a mini-game, with the first assignment always being an interview with the domain expert; (lower left) $c$. an assignment in which the student has to analyse and categorise video fragments of an intake interview; and (lower right) the dashboard that presents individual competence growth on generic and domain-specific professional competences and apparent preferences for specialisations (the latter available after $75 \%$ of gameplay).
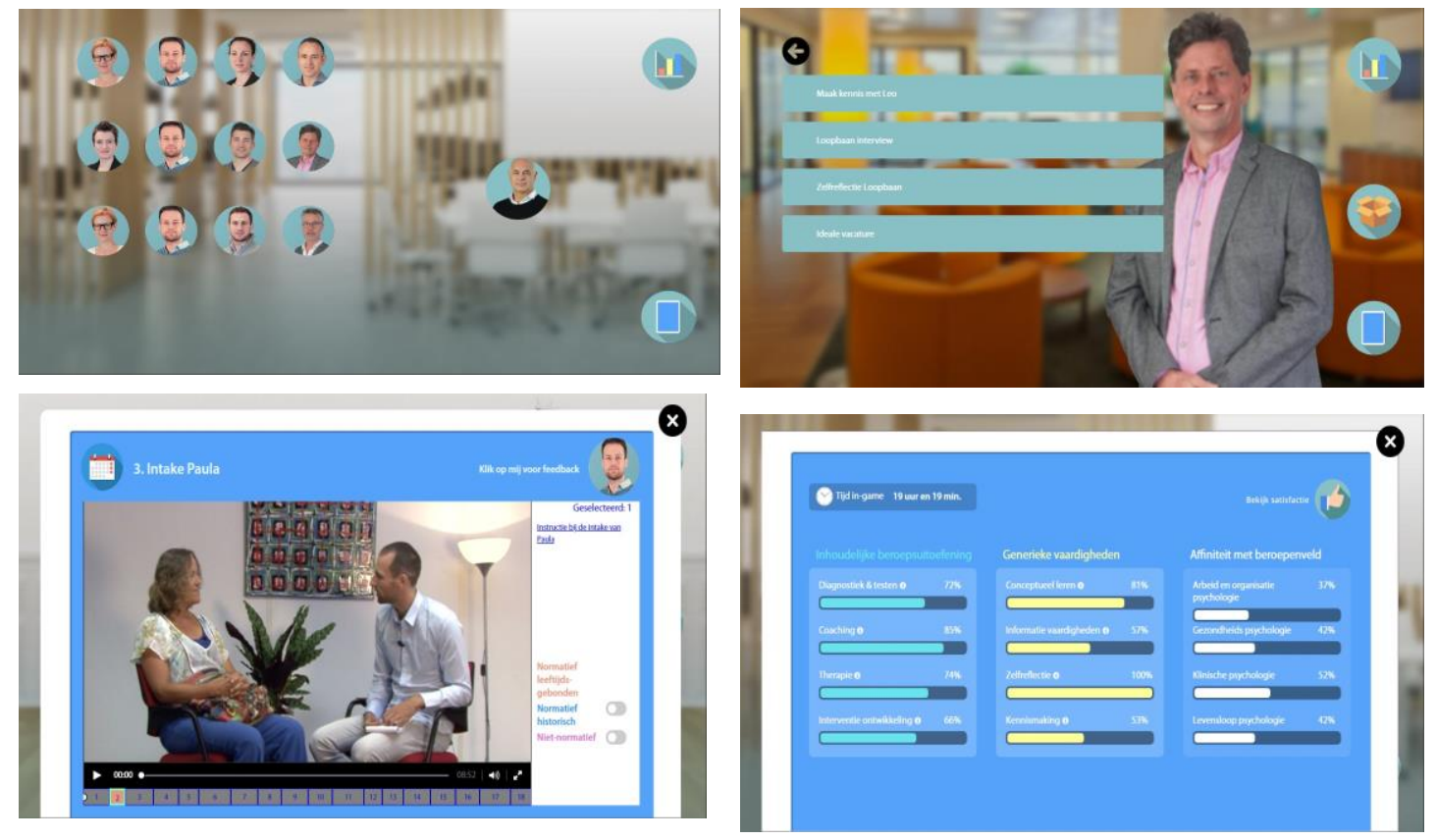

Figure 1. Screengrabs from mini-games for psychology awareness

We carried out an experimental study that had three main research questions: 1 . Does playing the minigames increase professional awareness of what the work of psychologists entails?; 2. Does offering a more flexible study path (more active learning) effect learning and satisfaction?; and 3. Does offering more resources (richer learning) effect learning and satisfaction? The next section will describe the research design of this study in some more detail.

\section{METHODOLOGY}

When participants decide to start gameplay (a mandatory component of this psychology course), as well as agree to participate in the study (by informed consent), our LMS redirects them to the EMERGO player environment. Before starting and after ending gameplay, EMERGO redirects them to a pre- and post-questionnaire respectively, that both are implemented and delivered in LimeSurvey. Both questionnaires contain sets of questions about professional psychology practice. The postquestionnaire furthermore contains items / scales measuring students' (subjective) appreciations of flow, authenticity, motivation, learnability, usability and satisfaction (with gameplay) as dependent variables.

Questionnaires: The (sixteen) MC items on psychology practice were developed by members of our own Psychology staff. We used all (23) items of the validated e-flow questionnaire ([14]) to measure 
perceived flow in online learning, for this study we have developed (19) items to measure perceived authenticity, used all (13) items of the validated IMI questionnaire ([15]) to measure motivation, have used (9) items from a validated questionnaire ([16]) to measure learnability, have used two scales (6 items) from the validated UMUX questionnaire ([17]) to measure usability, and finally have developed (7) items to measure attitude towards playing games. Cronbach's alphas found were 'good' to 'excellent' for all 5-point Likert scales, respectively $\alpha=.935$ for flow, $\alpha=.950$ for authenticity, $\alpha=.925$ for motivation, $\alpha=.816$ for learnability, $\alpha=.854$ for usability, and $\alpha=.817$ for attitude; and based on the variance of scores they all appear to have discriminative power. Average scores on the scales could therefore be used for further analyses. Finally, students were asked to evaluate the game content (EVAL_CONT) and gameplay (EVAL_GAME), scored on a 10-point scale.

Logging data: A dedicated research data component of the EMERGO authoring environment logged and extracted various gameplay activities as potentially interesting dependent variables. For this study we have looked into total playtime (in hours), the number of revisits to games (REV_GAME) and assignments (REV_ASS), the amount of (extra) resources opened (ORES_NR, EXRES_NR) with the average time (in minutes) they were open (ORES_TIM, EXRES_TIM), the number of deviations from the (standard) order of assignments (DEV_ASS), and an in-game performance score (PERF). This performance score is based on monitoring all errors made during gameplay and later transformed into $0-100 \%$ scores, with a $100 \%$ score indicating that no errors were made by student (most efficient learning) and a $0 \%$ score indicating 'random behavior' (or less) by student (least efficient learning), scores that are depending on the number of alternatives (nAlt) and amount of errors (nErr) for each activity. All assignment activities (total of 48 assignments, some having two or more sub assignments) were monitored, including a variety of tools like for answering MC questions, multi-select options, to categorize items (using drag-and-drop tools), for selecting text fragments, to generate pie charts, for axis-positioning, and others. Finally, we unobtrusively obtained (at the end of each assignment) student assessments of attractiveness (NICE_ASS) and task complexity (COMP_ASS) of assignments, that were scored on a 6-point scale.

Grades: After completing gameplay, participants had to take two partial exams to finish the course. At the time of writing of this article, for most participants only grades for the first part were available.

Data collection and analyses: Raw data from LimeSurvey, EMERGO and university's student administration were collated into an Excel sheet and stored securely to warrant student privacy by the principle investigator. An anonymized dataset (excluding student numbers) was imported into SPSS (version 24) were additional transformations (e.g., redirecting negative item scores, calculating averages) and statistical analyses were carried out.

\section{RESULTS}

In this section we present statistical descriptives on all main dependent variables (sub section 3.1), a paired samples t-test to establish a treatment effect of gameplay (sub section 3.2), and various univariate tests of variance (ANOVA's) to test for effects of conditions (variants of gameplay), including effect sizes (partial eta squares) when significant effects were found (sub section 3.3).

\subsection{Descriptives}

Tabel 1 presents an overview of statistical descriptives (minimal and maximal scores, means and standard deviations) for all dependent variables as were obtained from questionnaires and computer logging over all conditions of gameplay. The average time spend on playing the 12 mini-games is 17.15 hours (like we expected when designing the mini-games), although we see a lot of variance between students (ranging from about 4 to 40 hours). Participants appreciate authenticity, motivation, learnability and usability of playing the games with average scores between 6.8 (more than sufficient) and 7.6 (good). Content and gameplay are evaluated with averages around 7.3 but again with a large variance between students. The average attractiveness of assignments can be considered as "moderate to high" $(M=3.93)$ and the average complexity can be considered as "low to moderate" $(M=2.61)$.

Participants that had freedom to change the order of assignments hardly made use of this, with a maximum of only 4 deviations (DEV_ASS). Participants that had the possibility to open extra sources hardly made of this, with a maximum of only 6 extra resources opened (EXRES_NR). Finally, observed average scores for in-game flow and performance (both around 6.2) are sufficient, again with much discriminating variance between participants. 
Table 1. Descriptives for main dependent variables $(N=80)$

\begin{tabular}{l|r|r|r|r}
\hline Dependent variable & Min & Max & \multicolumn{1}{c}{$M$} & $\delta(S D)$ \\
\hline PLAYTIME (total, in hours) & 3.78 & 38.90 & 17.15 & 8.11 \\
REV_GAME & 0 & 31 & 9.58 & 8.19 \\
REV_ASS & 0 & 35 & 11.69 & 9.11 \\
ORES_NR & 45 & 130 & 92.36 & 14.34 \\
ORES_TIM (avg, in min) & 1.08 & 9.81 & 4.78 & 2.19 \\
EXRES_NR & 0 & 6 & .34 & 1.08 \\
EXRES_TIM (avg, in min) & .00 & 26.59 & .51 & 3.04 \\
DEV_ASS & 0 & 4 & .50 & .99 \\
NICE_ASS & 1.35 & 5.77 & 3.93 & .87 \\
COMPL_ASS & 1.00 & 4,54 & 2.61 & .72 \\
PERF & 47 & 76 & 61.91 & 5.78 \\
FLOW & 20.00 & 89.57 & 62.63 & 13.15 \\
AUTHENTICITY & 21.05 & 100.00 & 70.29 & 14.55 \\
MOTIVATION & 32.31 & 98,46 & 68.02 & 15.72 \\
LEARNABILITY & 43.33 & 100.00 & 69.65 & 11.65 \\
USABILITY & 20.00 & 100.00 & 76.04 & 15.37 \\
ATTITUDE & 31.43 & 100.00 & 71.50 & 13.28 \\
EVAL_CONT & 4 & 10 & 7.35 & 1.15 \\
EVAL_GAME & 1 & 10 & 7.25 & 1.78 \\
GRADE (first part, $N=77)$ & 2 & 10 & 6.51 & 1.55 \\
& & & & \\
\hline
\end{tabular}

The third sub section of results will present for which variables significant differences could be found between conditions.

\subsection{Treatment effect}

A paired samples t-test comparing the average scores on the pre-questionnaire items on psychological practice $(M=55.3 \%)$ with those on the post-questionnaire $(M=66.8 \%)$ shows a (highly) significant treatment effect with $t(79)=-4.228$ and $p<.001$, indicated by an almost $12 \%$ increase in awareness.

\subsection{Differences between groups}

Overall, most average scores appear not to differ that much between groups. The univariate analyses of variance we have ran, with experimental condition (or freedom of order / extra sources) as independent variables, yield significant effects for the in-game performance score, playtime and perceived authenticity as dependent variables.

Assignment order: Although both A+ groups (having freedom to choose their order of assignments) show higher in-game performance scores $\left(F(3,76)=2.521, p=0.064, \eta_{p}{ }^{2}=0.090\right)$, this difference is only 'marginally' significant. However, when regrouping participants in one group $A+$ (with $M=63.76$ and $\delta=5.65$ ) and one group A- (with $M=60.33$ and $\delta=5.47$ ) this difference becomes highly significant $\left(F(1,79)=7.590, p=0.007, \eta_{p}^{2}=0.089\right)$ with a medium effect size. Similarly, the $A+$ groups spend more total playtime than the A- groups $\left(F(3,76)=1.076, p=0.365, \eta_{p}^{2}=0.041\right)$, but this difference is not significant. However, when regrouping participants in one A+ group (with $M=18,76$ and $\delta=9,00$ ) and one A- group (with $M=15.75$ and $\delta=7.06$ ) this difference approaches a significant level $(F(1,79)=$ 2.798, $p=0.098, \eta_{p}^{2}=0.035$ ) with a small effect size (according to [12]).

Additional sources: We encountered some "marginally significant" differences with small effect sizes when similarly combining and comparing $\mathrm{B}+$ groups (having access to some more additional sources per assignment) with B- groups (just having one source per assignment) for perceived motivation $(M=$ 71.18 and $\delta=14.72$, versus $M=65.30$ and $\delta=16.21)$ and perceived authenticity scores $(M=73.62$ and $\delta=14.42$, versus $M=67.41$ and $\delta=14.21$ ), with small size effects, respectively $F(1,79)=2.857, p=$ $0.095, \eta_{p}^{2}=0.035$ for motivation, and $F(1,79)=3.748, p=0.057, \eta_{p}^{2}=0.046$ for authenticity.

\section{CONCLUSIONS}

Regarding our first research question, we may conclude that playing the mini-games is appreciated by participants as a more motivating and authentic learning alternative, and that playing increases the level 
of professional awareness. When comparing gaming variants (regarding the second and third research question), we found significant indications that providing some level of fixed (or logical) order in assignments might be beneficial for more efficient learning, and that providing sufficient background sources might contribute to a sense of authentic learning.

Preliminary results are to be taken with caution due to limitations in the current state of study. First of all, reported effects are of small effect size due to relatively small numbers of participants (16 to 21 per condition). Around 300 students will participate to guarantee sufficient effect sizes, but at the deadline for submitting this paper only 80 complete datasets could be analysed. Secondly, the within-game treatments A (more active) and B (richer) appear to be relatively small and scarcely noticed and / or used by gamers. Besides, skipping assignments or changing their order might not be a good indicator of more active learning when assignments (partly) build on each other. By skipping assignments, students might miss relevant information and make more errors, which then explains lower performance scores in A+ groups. It is likely that many gamers did not notice the presence of the 'extra sources' button, since only $10 \%$ made use of it. We need to continue this study with larger numbers of participants and / or repeat this study with much larger differences between conditions (e.g. by providing even less structure in one condition or by providing clearer access to even more additional sources).

We plan to look into some more qualitative data available like answers to the open questionnaire items, and will compare student evaluations of this revised introductory psychology course with the old course (that did not contain gaming as component). To include retention and throughput data is also recommended. The didactic scenarios and gaming mechanics designed seem to be of generic value when we want to increase professional awareness in other domains than psychology, and it would be interesting to see if similar game development and empirical studies could be replicated in other domains to generalise these finding. Notwithstanding such and other constraints, this study provides other empirical evidence for the enormous potential that professional games hold for more experiential education and further research in this area.

\section{ACKNOWLEDGEMENTS}

We thank our Psychology students who agreed to participate in this study, and our management to support development and research within the IP2 project.

\section{REFERENCES}

[1] Boersma, A., ten Dam, G., Volman, M., \& Wardekker, W. (2010). "This baby...it isn"t alive”: Towards a community of learners for vocational orientation. British Educational Research Journal, 36(1), 3-25.

[2] Freeman, S., Eddy, S.L, McDonough, M., Smith, M.K., Okoroafor, N., Jordt, H., \& Wenderoth, M.P. (2014). Active learning increases student performance in science, engineering, and mathematics. PNAS, 111(23), 8410-8415.

[3] Garris, R., Ahlers, R. \& Driskell, J. (2002). Games, motivation, and learning: a research and practice model. Simulation \& Gaming, 33(4), 441-467.

[4] Herrington, J., Oliver, R., \& Reeves, T.C. (2003). Patterns of engagement in authentic online learning environments. Australian Journal of Educational Technology, 19(1), 59-71.

[5] Hoekstra, H. A. (2011). A career roles model of career development. Journal of Vocational Behaviour, 78(2), 159-173.

[6] Meijers, F., Kuijpers, M., \& Gundy, C. (2013). The relationship between career competencies, career identity, motivation and quality of choice. International Journal for Educational and Vocational Guidance, 13(1), 47-66.

[7] Michael, J. (2006). Where's the evidence that active learning works? Advances in Physiology Education, 30(4), 159-167.

[8] Ritterveld, U., Cody, M., \& Vorderer, P. (2009). Serious games: Mechanisms and Effects. Routledge, New York, NY, USA.

[9] Ryan, R.M., \& Deci, E.L. (2000). Self-determination theory and the facilitation of intrinsic motivation, social development, and well-being. American Psychologist, 55, 68-78.

[10] Sherman, P. S., Sebora, T., \& Digman, L. A. (2008). Experiential entrepreneurship in the classroom: effects of teaching methods on entrepreneurial career choice intentions. Journal of Entrepreneurship Education, 11, 29-42.

[11] Wouters, P., \& van Oostendorp, H. (2013). A meta-analytic review of the role of instructional support in game-based learning. Computers \& Education, 60(1), 412-425.

[12] Cohen, J. (1988). Statistical power analysis for the behavioral sciences. Erlbaum Associates: Hillsdale.

[13] Nadolski, R. J., Hummel, H. G. K., Van den Brink, H. J., Hoefakker, R. E., Slootmaker, A., \& Storm, J. (2008). EMERGO: A methodology and toolkit for developing serious games in higher education. Simulation \& Gaming, 39(3), 338-355. 
[14] Fang, X., Zhang, J., \& Chan, S. (2013). International Journal of Human-Computer Interaction, 29, 456-470.

[15] Ryan, R.M., \& Deci, E.L. (2000). Self-determination theory and the facilitation of intrinsic motivation, social development, and well-being. American Psychologist, 55, 68-78.

[16] Nadolski, R.J., \& Hummel, H.G.K. (2017). Retrospective cognitive feedback for progress monitoring in serious games. British Journal of Educational Technology, 48 (6), 1368-1379.

[17] Lewis, J.R., Utesch, B.S., \& Maher, D.E. (2015). Measuring Perceived Usability: The SUS, UMUX-LITE, and AltUsability. International Journal of Human-Computer Interaction, 31, 496-505. 